\title{
Discrepancy between the Clinical Image and Pathological Findings of Non-Small Cell Lung Cancer Harboring an Epidermal Growth Factor Receptor Gene Mutation That Was Surgically Resected after Gefitinib Treatment
}

\author{
Yasuhiro Chikaishi ${ }^{a}$ Hidetaka Uramoto $^{a}$ Soichi Oka $^{a}$ Shuya Nagata ${ }^{b}$ \\ Hidehiko Shimokawa ${ }^{a}$ Tomoko So $^{a}$ Sohsuke Yamada ${ }^{c}$

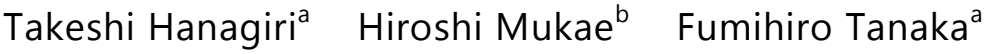 \\ ${ }^{a}$ Second Department of Surgery, and Departments of ${ }^{b}$ Respiratory Medicine and \\ ${ }^{\mathrm{C}}$ Pathology, School of Medicine, University of Occupational and Environmental Health, \\ Kitakyushu, Japan
}

\section{Key Words}

Gefitinib - Epidermal growth factor receptor - Non-small cell lung cancer - Pathological effect

\begin{abstract}
We herein describe a discrepancy between the clinical image and pathological findings in a non-small cell lung cancer patient with an epidermal growth factor receptor (EGFR) mutation who underwent surgical resection after gefitinib treatment. The patient was a 66-year-old female with c-stage IIIA lung adenocarcinoma harboring an EGFR gene mutation; she was surgically treated after receiving gefitinib. The pathological examination revealed adenocarcinoma, and the pathologically therapeutic effect was considered to be slight or of no response. EGFR T790M mutation and MET amplification were not present. The pathologically therapeutic effect is generally well correlated with the response rate after induction therapy. In this case, there was a discrepancy between the clinical image and pathological findings. Our findings, therefore, raise questions about the role of surgery after EGFR-tyrosine kinase inhibitor treatment.

(C) 2014 S. Karger AG, Basel
\end{abstract}




\section{Introduction}

The current standard of care for patients with locally advanced non-small cell lung cancer (NSCLC) is concurrent chemoradiotherapy (CRTx) or surgery with CRTx; however, the most effective treatment for patients with locally advanced (stage III) NSCLC remains controversial. When concurrent CRTx followed by surgery is performed, patients with a pathological complete response tend to show a longer overall survival than those without a pathological complete response $[1,2]$.

Epidermal growth factor receptor (EGFR)-tyrosine kinase inhibitors (TKIs) are effective against more than $70 \%$ of advanced NSCLC with EGFR gene mutations [3-5]. Some authors have reported the usefulness of surgical resection after gefitinib treatment for responding patients [6-8]. However, almost all the reported patients who underwent surgical resection after gefitinib treatment had distant metastasis.

In this report, we describe a patient in whom the pathological effect was a slight pathological response; however, she had a partial response (PR) after gefitinib treatment for NSCLC harboring an EGFR gene mutation. This finding raises questions about the role of surgery after gefitinib treatment.

\section{Case Report}

A 66-year-old female never-smoker with no significant medical history was referred to our hospital for the evaluation of an abnormal shadow observed on a chest X-ray film. Chest computed tomography (CT) revealed a $4.4-\mathrm{cm}$ primary mass in the left upper lobe beside the main pulmonary artery and the growth of mediastinal lymph nodes (cT2aN2M0 stage IIIA) (fig. 1a, b). Fluorodeoxyglucose positron emission tomography (FDG-PET) showed FDG uptake in the mass with a maximal standardized uptake value (SUV) of 12.2, and in mediastinal lymph nodes with an SUV of 6.6 (fig. 1c). She was diagnosed with lung adenocarcinoma (fig. 2a) by a transbronchial lung biopsy. The L858R mutation in exon 21 of the EGFR gene was identified in the primary lung tumor. We gave the patient and her family three possible treatment options: concurrent CRTx (using standard platinum-based doublet chemotherapy), induction chemotherapy followed by surgery, or gefitinib therapy. They selected gefitinib therapy. Therefore, systemic chemotherapy with gefitinib (250 mg/body) was performed.

After 3 months of gefitinib treatment, a radiological CT evaluation revealed that there was a PR to gefitinib (regression rate was 35\%) (fig. 1d, e), and a PET scan image showed positive accumulation of FDG (SUV max. 4.0) in the tumor (fig. 1f). Because of the good response, the patient wanted to undergo surgery. The gefitinib administration was stopped 2 weeks prior to surgery so that the drug would not interfere with tissue repair. We performed a left upper lobectomy and a combined resection of S6, which was involved by the tumor, and a systematic lymphadenectomy. Because the initially swollen lymph nodes had become thickened fibrous scars owing to the response to gefitinib, it was difficult to expose the superior trunk of the pulmonary artery. Finally, complete resection was achieved. The postoperative course was uneventful. The pathological examination revealed adenocarcinoma in the primary site, hilar lymph node (\#12u) and mediastinal lymph node (\#5), which also involved extra nodal disease. The tumor size was $37 \times 32 \times 30 \mathrm{~mm}$, and the left S6 was considered to have higher than interlobar involvement (pT2aN2M0 stage IIIA). The pathologically therapeutic effect was considered to be slight or of no response (fig. $2 \mathrm{~b}$ ). EGFR 
Chikaishi et al:: Discrepancy between the Clinical Image and Pathological Findings of NSCLC Harboring an EGFR Gene Mutation That Was Resected after Gefitinib

T790M mutation and MET amplification, which are often acquired following gefitinib treatment, were not observed [9].

Radiation therapy was performed for the mediastinal lymph nodes because of the extranodal invasion. Ten months after the operation, the patient developed recurrence in the cervical lymph nodes and multiple pulmonary metastases. Gefitinib therapy was tried again, and the effect was a PR of the lymph nodes and complete response of the pulmonary metastases. She is doing well and is still being treated with gefitinib, 16 months after surgery.

\section{Discussion}

Generally, when preoperative therapy is considered to have achieved a good response, the pathological effect is a moderate or complete pathological response. When induction therapy is performed, pathological downstaging and a pathological complete response are independent factors for a favorable overall survival $[1,2]$. Some large-scale studies have been previously reported regarding preoperative EGFR-TKI in patients with early-stage NSCLC [10-13]. One such study mentioned the pathological response, but the clinical response did not clearly correlate with the pathological response in detail [13]. In addition, no large-scale studies have thus far been reported regarding the use of preoperative EGFRTKI in patients with advanced NCSLC. There have been a few reports regarding the association between the clinical response after induction therapy and the pathological effect after surgery in advanced NCSLC. There were 12 patients who underwent surgery after gefitinib treatment for advanced NCSLC. Nine of these patients harbored EGFR gene mutations, and 4 of them had a known pathological effect. All 4 of these patients had a PR to induction therapy in the clinical images, and 3 out of the 4 had a complete pathological response, while 1 had a moderate pathological response [6-8].

In this report, there was a discrepancy between the clinical image and pathological findings in an NSCLC patient, harboring an EGFR gene mutation, who underwent surgical resection after gefitinib treatment. It is possible that the pathological effect after EGFR-TKI treatment might be overestimated. In fact, of the previously reported 4 cases, 3 were shortterm outcomes, and 1 patient developed recurrence in the brain 2 years and 4 months after surgery [6-8].

In conclusion, surgery following induction therapy using EGFR-TKI should be carefully considered, even if the NSCLC harbors an EGFR gene mutation and the clinical imaging shows a complete clinical response.

\section{References}

1 Mouillet G, Monnet E, Milleron B, Puyraveau M, Quoix E, David P, Ducoloné A, Molinier O, Zalcman G, Depierre A, Westeel V: Pathologic complete response to preoperative chemotherapy predicts cure in earlystage non-small-cell lung cancer: combined analysis of two IFCT randomized trials. J Thorac Oncol 2012;7:841-849.

-2 Pataer A, Kalhor N, Correa AM, Raso MG, Erasmus JJ, Kim ES, Behrens C, Lee JJ, Roth JA, Stewart DJ, Vaporciyan AA, Wistuba II, Swisher SG: Histopathologic response criteria predict survival of patients with resected lung cancer after neoadjuvant chemotherapy. J Thorac Oncol 2012;7:825-832.

-3 Mitsudomi T, Kosaka T, Endoh H, Horio Y, Hida T, Mori S, Hatooka S, Shinoda M, Takahashi T, Yatabe Y: Mutations of the epidermal growth factor receptor gene predict prolonged survival after gefitinib treatment in patients with non-small-cell lung cancer with postoperative recurrence. J Clin Oncol 2005;10:2513-2520.

4 Maemondo M, Inoue A, Kobayashi K, Sugawara S, Oizumi S, Isobe H, Gemma A, Harada M, Yoshizawa H, Kinoshita I, Fujita Y, Okinaga S, Hirano H, Yoshimori K, Harada T, Ogura T, Ando M, Miyazawa H, Tanaka T, 
Saijo Y, Hagiwara K, Morita S, Nukiwa T: Gefitinib or chemotherapy for non-small-cell lung cancer with mutated EGFR. N Engl J Med. 2010;362:2380-2388.

5 Chen G, Feng J, Zhou C, Wu YL, Liu XQ, Wang C, Zhang S, Wang J, Zhou S, Ren S, Lu S, Zhang L, Hu CP, Hu C, Luo Y, Chen L, Ye M, Huang J, Zhi X, Zhang Y, Xiu Q, Ma J, Zhang L, You C: Quality of life (QoL) analyses from OPTIMAL (CTONG-0802), a phase III, randomised, open-label study of first-line erlotinib versus chemotherapy in patients with advanced EGFR mutation-positive non-small-cell lung cancer (NSCLC). Ann Oncol 2013;24:1615-1622.

6 Hishida T, Nagai K, Mitsudomi T, Yokoi K, Kondo H, Horinouchi H, Akiyama H, Nagayasu T, Tsuboi M: Salvage surgery for advanced non-small cell lung cancer after response to gefitinib. J Thorac Cardiovasc Surg 2010;140:e69-e71.

7 Takamochi K, Suzuki K, Sugimura H, Funai K, Mori H, Bashar AH, Kazui T: Surgical resection after gefitinib treatment in patients with lung adenocarcinoma harboring epidermal growth factor receptor gene mutation. Lung Cancer 2007;58:149-155.

-8 Hashimoto K, Horinouchi H, Ohtsuka T, Kohno M, Izumi Y, Hayashi Y, Nomori H: Salvage surgery for a superresponder by gefitinib therapy for advanced lung cancer. Gen Thorac Cardiovasc Surg 2012;60:851-854.

-9 Uramoto H, Shimokawa H, Hanagiri T, Kuwano M, Ono M: Expression of selected gene for acquired drug resistance to EGFR-TKI in lung adenocarcinoma. Lung Cancer 2011;73:361-365.

10 Lara-Guerra H, Waddell TK, Salvarrey MA, Joshua AM, Chung CT, Paul N, Boerner S, Sakurada A, Ludkovski O, Ma C, Squire J, Liu G, Shepherd FA, Tsao MS, Leighl NB: Phase II study of preoperative gefitinib in clinical stage I non-small-cell lung cancer. J Clin Oncol 2009;36;27:6229-6236.

-11 Haura EB, Sommers E, Song L, Chiappori A, Becker A: A pilot study of preoperative gefitinib for early-stage lung cancer to assess intratumor drug concentration and pathways mediating primary resistance. J Thorac Oncol 2010;5:1806-1814.

12 Rizvi NA, Rusch V, Pao W, Chaft JE, Ladanyi M, Miller VA, Krug LM, Azzoli CG, Bains M, Downey R, Flores R, Park B, Singh B, Zakowski M, Heelan RT, Shen R, Kris MG: Molecular characteristics predict clinical outcomes: prospective trial correlating response to the EGFR tyrosine kinase inhibitor gefitinib with the presence of sensitizing mutations in the tyrosine binding domain of the EGFR gene. Clin Cancer Res 2011;15;17:3500-3506.

$\longrightarrow 13$ Schaake EE, Kappers I, Codrington HE, Valdés Olmos RA, Teertstra HJ, van Pel R: Tumor response and toxicity of neoadjuvant erlotinib in patients with early-stage non-small-cell lung cancer. J Clin Oncol 2012 30;22:2731-2738. 
Chikaishi et al.: Discrepancy between the Clinical Image and Pathological Findings of NSCLC Harboring an EGFR Gene Mutation That Was Resected after Gefitinib
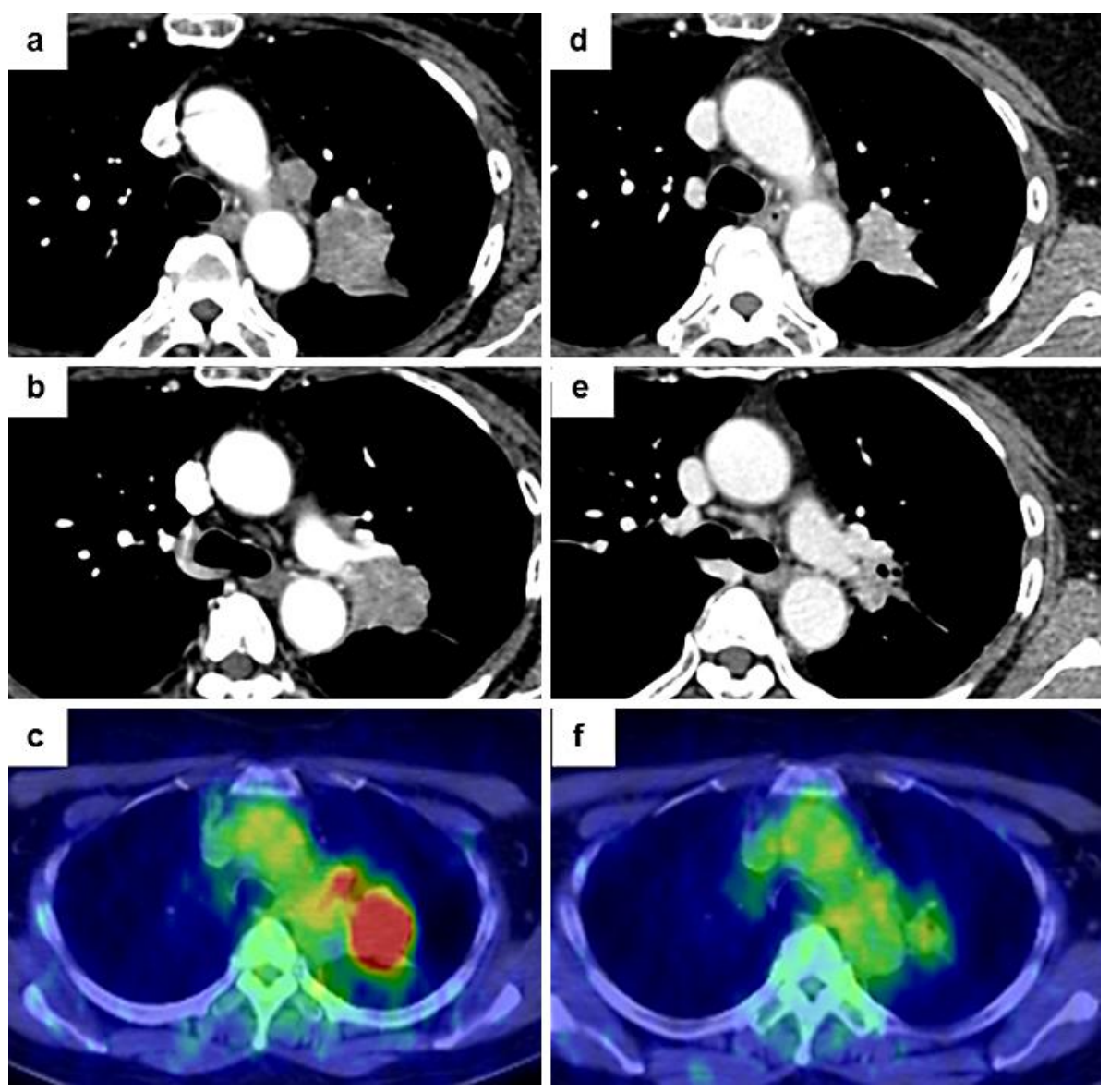

Fig. 1. Radiological evaluation by CT and PET scans. a-c Before treatment. a A mediastinal lymph node (\#5) is observed. b A primary lesion in the left upper lobe can be seen invading the main pulmonary artery. c A PET scan image shows positive accumulation of FDG in the tumor. $\mathbf{d}-\mathbf{f}$ After gefitinib treatment. $\mathbf{d}$ The mediastinal lymph node (\#5) shows good regression. e Mild regression of the primary lesion and lymph node metastasis can be seen. $f$ A PET scan image shows positive accumulation of FDG in the tumor. 


\section{Case Reports in Oncology}

\begin{tabular}{l|l}
\hline Case Rep Oncol 2014;7:126-131 \\
\hline DOI: 10.1159/000360154 & $\begin{array}{l}\text { ○ 2014 S. Karger AG, Basel } \\
\text { www.karger.com/cro }\end{array}$ \\
\hline
\end{tabular}

Chikaishi et al.: Discrepancy between the Clinical Image and Pathological Findings of NSCLC Harboring an EGFR Gene Mutation That Was Resected after Gefitinib
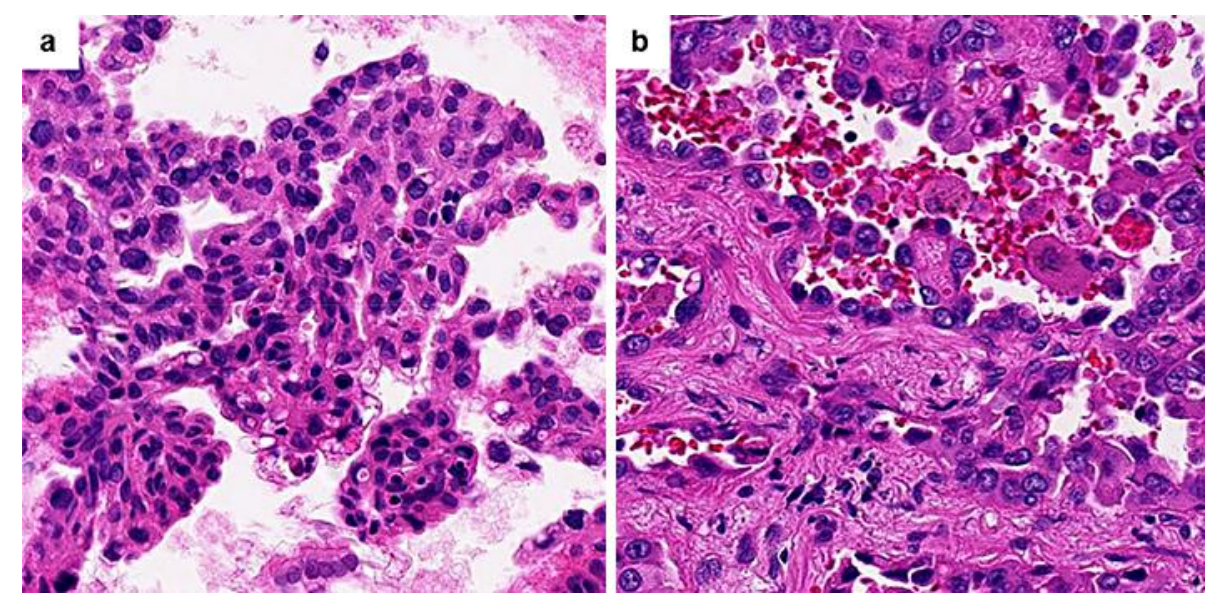

Fig. 2. The histological evaluation. a The histological findings of a section obtained by transbronchial lung biopsy (hematoxylin-eosin stain) reveal the proliferation of atypical cuboid-columnar epithelial cells with enlarged hyperchromatic nuclei, arranged predominantly in a papillary growth pattern. $\mathbf{b}$ The histological findings of the resected primary tumor (hematoxylin-eosin stain) show a papillary proliferation of viable adenocarcinoma cells, admixed with a small number of nonviable swollen carcinoma cells, thus suggestive of a slight therapeutic effect. 